\title{
Comparative study between auto polymerized acrylic denture and heat cure acrylic denture on oral mucosa
}

\author{
Howlader $\mathrm{MBU}^{1 *}$, Hossain $\mathrm{MA}^{2}$, Malik MAM${ }^{3}$, Mostafa $\mathrm{MM}^{4}$, Wadud MA
}

\section{AFFILIATION:}

1. Prof. Dr. Mohammod Borhan Uddin Howlader Prof. \& Head Dept. of Prosthodontics,

Dhaka Dental College. Bangladesh

2. Dr. Md. Amzad Hossain,

Associate Professor Dept. of Prosthodontics, BSMMU. Bangladesh

3. Dr. Md. Abdul Muttalib Malik,

Assistant Prof. Dept. of Periodontology \& Oral Pathology, Dhaka Dental College.

4. Dr. Md. Mohammadullah Mostafa, Medical Officer, Dept. of Prosthodontics, BSMMU.

5. Dr. Md. Ashikul Wadud,

Assistant Prof. Dept. of Prosthodontics, Update Dental College \& Hospital.

\section{Article info.}

Received: 18 May 2020

Accepted: 30 May 2020

Volume: Vol-10, Issue-2, October 2020

DOI:

https://doi.org/10.3329/updcj.v10i2.50176

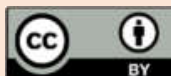

(C) Authors retain copyright and grant the journal right of first publication with the work simultaneously licensed under Creative Commons Attribution License CC - BY 4.0 that allows others to share the work with an acknowledgment of the work's authorship and initial publication in this journal.

https://creativecommons.org/licenses/by/4.0/

Publisher: Update Dental College, Dhaka, Bangladesh

Web: www.updatedentalcollege.edu.bd

E-mail: updcj@hotmail.com

\author{
* Corresponding Author \\ Prof Dr. Mohammod Borhan Uddin Howlader, \\ Prof \& Head Dept. of Prosthodontics, \\ Dhaka Dental College. Bangladesh \\ E-mail:dr.borhan1975@gmail.com. \\ Contact No: +8801712532753
}

\section{Citation}

Howlader MBU, Hossain MA, Malik MAM, Mostafa MM, Wadud MA, Comparative study between auto polymerized acrylic denture and heat cure acrylic denture on oral mucosa,UpDCJ;10(2):18-20 DOI: https://doi.org/10.3329/updci.v10i2.50176

\begin{abstract}
:
The aim of this comparative study was to evaluate the effectiveness of auto polymerized acrylic denture on oral mucosa. The total 40 partially edentulous patients were included in this study and randomly divided into two groups. Group A consisted of 20 patients and group B consisted of 20 patients who were attending in the Department of Prosthodontics and they were treated by auto polymerized and heat cure acrylic denture respectively. Follow up was done after 1 weeks and 4 weeks of insertion of denture. Data were recorded by using predesigned data collection sheet and analyzed by using SPSS. In case of autopolymerized acrylic denture, after 4 weeks of treatment most of the cases showed oral mucosal changes which could be turned to malignancy $(p<0.5)$. But in case of heat cure acrylic denture satisfactory mucosal changes were not found. However, heat cure acrylic denture did not show any statistically significant difference ( $p>0.5)$. So it can be concluded that there is a direct adverse reaction between autopolymerized acrylic denture and oral mucosa.
\end{abstract}

KEY WORDS: Auto polymerized acrylic denture, heat cure acrylic denture, oral mucosa.

\section{INTRODUCTION:}

Polymerized acrylic resin material of these denture is a potential pathogenic factor to the oral cavity mucosa which is in contact with it. It is considered that the mucosal irritation may be caused by denture trauma, a mycotic infection or toxic action of some components of acrylic materials $\mathrm{s}^{1-2}$.

These resin materials may be either content self polymerizing or heat polymerizing $\operatorname{resin}^{1-2}$. Acrylic resin denture contain Methyl Methacrylate (MMA) as residual monomer. MMA has the potential to elicit irritation, inflammation and allergic response of the oral mucosa ${ }^{3-6}$. Further residual monomer in capable of producing both stomatitis and angular chelitis.

When exposed to MMA in the Dental Clinic, Dentist and other Dental staff appear to occasionally suffer hypersensitivity, asthmatic reactions, local neurological symptoms, irritant and local dermatological reactions.

The reason for the higher residual monomer content in the autopolymerized acrylic resin is due to low degree of conversion achieved by the use of chemical The reason for the higher residual monomer contenin the autopolymerized acrylic resin is due to low degree of conversion achieved by the use of chemical activaton as opposed to that generated by heat activation. Residual monomer has been shown to adversely effect mechanical properties of acrylic resins. In addition, residual monomer can elicit 
irritation, inflammation and an allergic response by oral mucosa?.

In many studies, a good correlation has been demonstrated between the amount of Methyl Methacrylate monomer into polymer remaining in acrylic resin after polymerization and the methyl methacrylic concentration leached from acrylic resin ${ }^{8}$.

Residual monomer resulting from incomplete conversations of monomer into polymer, has the potential to elicit irritation, inflammation and an allergic response by oral mucosa. Clinical sign and symptoms most frequently reported include-

the mucosa and tongue ${ }^{9}$.

erythema, erosion of oral mucosa and a sensation on Methodology: Fourty (40) partially edentulous patients were selected under the inclusion criteria and they were divided case and control group. The 20 cases subject denture were fabricated by autopolymerized acrylic resin and 20 control subjects denture were fabricated by heat cure acrylic resin. Clinical examination and photograph were taken to facilitate assessment of clinical response. Histological evaluation was done after 4 weeks of insertion of the denture in both cases and controls group.

After complete oral examination, clinical findings were evaluated after one week and four weeks of insertion of denture. After clinical and histological evaluation, all relevant date were recorded from the participants using pre-designed data collection sheet. Data were analyzed by using statistical package for social sciences (SPSS) version 12.0 software program. Study Parameters: Color of the Mucosa, Color of the Lesion, Size of the Lesion, Histopathology.

\section{RESULTS:}

A total 40 subjects aged from 31 to 60 years were included and they were divided into equal halves. They were treated by autopolymerized acrylic denture (case group) and heat cure acrylic denture (control group) respectively. Patients were evaluated in terms of variable- Age, Sex, Color of the mucosa, Color of the Lesion, Size of the lesion,Histopathology, Histopathological evaluation was done at the end of the study of four weeks.

Table I: Distribution of denture wearers patient's according to age $(n=40)$

\begin{tabular}{ccc}
\hline Age & Frequency & Percentage \\
\hline $\mathbf{3 1 - 4 0}$ & 6 & 15 \\
\hline $\mathbf{4 1 - 5 0}$ & 12 & 30 \\
$\mathbf{5 1 - 6 0}$ & 22 & 55 \\
\hline
\end{tabular}

Table I- Showed that 55\% of the respondents were $51-60$ years of age, followed by $30 \%$ and $15 \%$ were $41-50$ years and $31-40$ years of age respectively.

Table II: Oral Mucosa changes after 1 month of insertion in autopolymerized denture $(n=20)$

\begin{tabular}{lcc}
\hline \multicolumn{1}{c}{ Type of Lesion } & $\begin{array}{c}\text { Number of } \\
\text { Patient }\end{array}$ & Percentage \\
\hline Stomatitis & 6 & $30 \%$ \\
\hline Red Lesion & 5 & $25 \%$ \\
\hline Flabby mucosa & 4 & $20 \%$ \\
\hline Oral Ulceration & 3 & $15 \%$ \\
\hline Red Lesion and & 2 & $10 \%$
\end{tabular}

stomatitis

Table II- showed that in case of autopolymerized acrylic denture out of 20 patients, stomatitis developed in $6(30 \%)$ patients, Red lesion 5 (25\%), Flabby mucosa 4 (20\%), Oral ulceration 3 (15\%), Red lesion and stomatitis $2(10 \%)$ patients respectively.

Table III: Oral mucosal change after one month of insertion in heat cure acrylic denture $(n=20)$

\begin{tabular}{lcc}
\hline Surface of the Mucosa & Number & Percentage \\
\hline Normal mucosa & 15 & $75 \%$ \\
\hline Ulceration & 3 & $15 \%$ \\
\hline Irregular Surface & 2 & $10 \%$ \\
\hline
\end{tabular}

Table III- showed that in case of heat cure acrylic denture out of 20 patients, normal mucosa 15 (75\%), Ulceration $3(15 \%)$ and Irregular surface $2(10 \%)$ patient's were found respectively.

Table IV: Assessment of oral mucosal changes by histopathology in autopolymerized acrylic denture $(n=20)$

\begin{tabular}{lcc}
\multicolumn{1}{c}{ Findings } & $\begin{array}{c}\text { Number of } \\
\text { Patient }\end{array}$ & Percentage \\
\hline $\begin{array}{l}\text { Squamous } \\
\text { hyperplasia }\end{array}$ & 6 & $30 \%$ \\
\hline $\begin{array}{l}\text { EPIthelial dysplasia } \\
\begin{array}{l}\text { Denture induced } \\
\text { hyperplasia }\end{array}\end{array}$ & 4 & $20 \%$ \\
\hline Papillary hyperplasia & 2 & $15 \%$ \\
\hline Normal Mucosa & 5 & $10 \%$ \\
\hline
\end{tabular}

The table IV- showed that in case of autopolymerized acrylic denture out of 20 patients, squamous hyperplasia developed 6 (30\%), epithelial dysplasia in $4(20 \%)$, denture hyperplasia found in $3(15 \%)$, papillary hyperplasia $2(10 \%)$ and $5(25 \%)$ had normal mucosa.

Table V: Association of oral mucosal changes by histopathology in autopolymerized and heat cure acrylic denture $(n=40)$

\begin{tabular}{lll}
\multicolumn{1}{c}{ Findings } & \multicolumn{1}{c}{ Case } & \multicolumn{1}{c}{ Controls } \\
\hline Changes & $16(80 \%)$ & $3(15 \%)$ \\
\hline No change & $4(20 \%)$ & $17(85 \%)$ \\
\hline
\end{tabular}

Statistically analysis was done by chi-square test $n=$ number of patient * $p=<0.05 n s=$ not significant , Chi-square $=13.54, P=0.002$, $\mathrm{OR}=12.67, \mathrm{RR}=9.40$

Table $\mathrm{V}$ - chi-square showed that there is significant association of oral mucosal changes in study group $(p<0.05)$.

DISCUSSION:

The comparative study was evaluate to observe the 
response on autopolymerized and heat cure acrylic denture on oral mucosa by clinical sign symptoms and histopathology. According to table II four weeks after treatment, in case of 20 autopolymerized acrylic denture, stomatitis developed in $6(30 \%)$ patients. However Jaenk Vong et al (2010) reported denture related oral mucosal lesion denture developed in $50 \%$ cases. The reason of dissimilarities might be due to short study period and less sample size.

According to table III showed that in case of heat cure acrylic denture, 31 (15\%) cases ulceration were found. 2 (10\%) cases developed irregular surface and rest 15 (75\%) were normal mucosa.

It is similar to the study of MC Cabe J F, Basker R.M. In their study $15 \%$ mucosal change were found in heat cure acrylic denture. According to table IV in case of autopolymerized acrylic denture after 4 weeks of insertion, histopathology of oral mucosal lesion showed that $25 \%$ had normal mucosa but $75 \%$ had some changes. It is similar with the study of Linaera M, Dasilva F. This study showed that oral mucosa lesion were developed in $30-50 \%$ case. Table $V$ showed that chi-square showed that there is significant association of oral mucosa changes in study group $(p<0.05)$.

\section{CONCLUSION AND RECOMMENDATION:}

It can be concluded that these is a direct advaerse reaction by autopolymerized acrylic denture on oral mucosa. So heat cure acrylic resin should be used for the replacement of partially edentulous patients.

\section{REFERENCES:}

1. Filiz A. Keyf, A Ihsan Keyf. Harmful effects of methyl methacrylate and formaldehyde from acrylic resin denture base materials. The Saudi Dental Journal 1998; 10 (1): $23-28$.

2. Mohammad M. Sadmoon, Nada Z Mohammed, Alia O Al- Omary. Residual monomer and transverse strength evaluation of auto polymerized acrylic resin with different polymerization. Al-rafidain Dental Journal 2007; 7:30-34.

3. Ureporn Kedjarune, nongluk charoenworaluk, sittichai koontogkaew. Release of methyl methacrylate from heat cured and auto polymerized resins. Cytotoxicity testing related to residual monomer. Australian dental journal 1999; $\quad 44: \quad 25-29$. https://doi.org/10.1111/j.1834-7819.1999.tb00532.x PMid:10217017

4. Janina Habib Jonge, Eunice Teresinha Giampaolo, Analucia Machado et. Al. Cytotoxicity of denture base acrylic resigns: A literature review. The journal of prosthetic dentistry 2003; 90: 190-193. https://doi.org/10.1016/S0022-3913(03)00349-4

5. Glunta JE, Zablotsky N. Allergic stomatitis caused by self-polymerizing resin. Oral surg 1976; 41: 631-636. https://doi.org/10.1016/0030-4220(76)90315-7
6. Stungis TE, Fink JN. Hypersensitivity to acrylic resin. J Prosthet Dent 1969;22:425-428. https://doi.org/10.1016/0022-3913(69)90209-1

7. Kotilainen R. Stomatitis prothetica and allergy. Proc Finn Dent Soc 1972;68:136.

8. Tatiana Siqueira Goncalves, Mario A morganti, Luis C, Campos et. Al. Allergy to auto polymerized acrylic resin in an orthodontic patient. American orthodontic dento facial orthopedic 2006; 29: 431-435. https://doi.org/10.1016/j.ajodo.2005.10.017 PMid:16527642

9. Emin Murat Canger et. Al. Denture Related Hyperplasia: A clinical study of a Turkish Population Group. Braz Dent $\begin{array}{lllll}\text { J } & \text { (2009) } & 20 & \text { (3): } & \text { 243-248. }\end{array}$ https://doi.org/10.1590/S0103-64402009000300013 PMid:19784472 